\title{
Qualidade e Ergonomia do local de trabalho contribuindo para o rendimento do grupo criativo no ambiente empresarial
}

\author{
Quality and ergonomics of the workplace contribute to group revenue in the creative \\ business environment
}

HORI, Jéssica

Especialista em Gestão do Design; Universidade Estadual de Londrina

jessicahori@gmail.com

BARROS, Vanessa Tavares de Oliveira

Doutoranda em Engenharia e Gestão do Conhecimento; Universidade Federal de Santa Catarina / Docente da Universidade Estadual de Londrina

vanessa@uel.br

FIALHO, Antônio Francisco

Doutor em Engenharia; Universidade Federal de Santa Catarina

fapfialho@gmail.com

\begin{abstract}
Resumo
O presente artigo tem como objetivo, esclarecer alguns aspectos relacionados à qualidade do ambiente de trabalho e à criatividade com colaboração da ergonomia, visa também verificar como o grupo criativo pode ser melhor inserido no ambiente empresarial, onde o cotidiano é geralmente formal e burocrático e o grupo em questão necessita de constante renovação de idéias e estímulos externos para o bom desenvolvimento de seu trabalho. É possível verificar por meio dos resultados alcançados a importância de ações no ambiente de trabalho de equipes.
\end{abstract}

Palavras Chave: Ergonomia; Qualidade; Criatividade; Grupos criativos.

\begin{abstract}
This article aims to clarify some aspects of the quality of work environment and creativity collaboration with the ergonomics, and also aims to verify how the creative group can best be inserted in the business environment, where daily life is extremely formal and bureaucratic and the group in question needs constant renewal ideas renewal and external stimulation for proper development of their work. There is a growth in the study of creativity in post-industrial society because of its importance in replacement of manual laborers; some aspects have been addressed here: psychological, social and cultural rights of the creative process. You can check the results achieved by the importance of actions in the workplace team.
\end{abstract}

Keywords: Ergonomic; Quality; Creativity.

\section{Introdução}

Profissionais da área de criação como marketing, publicitários, projetistas, designers e arquitetos, estão cada vez mais presentes em empresas consideradas paternalistas. 
Vieram para participar do crescimento intelectual dentro da corporação e oferecer ao cliente, seja ele qual for, soluções inteligentes e diferenciadas das existentes no mercado.

As empresas por necessitarem de inovações, estão investindo cada vez mais em capital intelectual, entretanto, muitas vezes não conseguem assimilar todo o potencial do profissional que ali se encontra e ou o mesmo não sabem expressar de forma satisfatória, o que está realmente em suas competências, gerando um mau aproveitamento da capacidade e conhecimento total do mesmo.

A fim de facilitar a compreensão e delimitar a pesquisa teórica, a seguir serão definidos alguns termos que possam ser de entendimento vago e/ou gerar ambigüidade:

Criatividade - Gomes (1994, p.57) conceitua como habilidade que se expressa através de individualidades, autenticidades e honestidade de percepção. Para Schwartz (1992), a visão antropocêntrica da criatividade tem sido questionada e levado em conta o contexto social e cultural como grande influencia para este indivíduo.

Inovação - do ponto de vista das empresas submersas em alta competitividade, onde se diferencia pelo capital humano, a inovação vem sendo cada dia mais exigida, que nada mais seria que uma visão para utilização ou produção de um bem que beneficiem de algum modo a organização, geralmente adquirida através do uso da criatividade.

Ambiente de Trabalho - (FARIA; ALENCAR, 1996, p.51) são todos os fatores que cercam o indivíduo, incluindo as pessoas com as quais se relacionam no dia-a-dia de trabalho, entretanto a proposta de alteração deste trabalho será apenas no ambiente físico e seus elementos de dimensões, arranjo dos espaços, mobiliários, iluminação, ventilação, conforto térmico e acústico.

Organizações - segundo Zacharias $(2009$, p.36) são o tipo de sistema social predominante das sociedades industrializadas, onde a sociedade moderna se caracteriza pelas organizações tendo-se esta como o estabelecimento de uma estrutura formal de autoridade, mediante a qual se definem, dispõem e coordenam as fases e métodos de trabalho para atingir um objetivo.

Tais organizações, acostumadas à sua formalidade excessiva, cargas horárias extensas e falta de atenção e cuidado para com o ressinto, muitas vezes não há o planejamento adequado deste local. Percebe-se que não estão preparadas para receber os profissionais de criação, que requerem de ambiente propício à evolução de idéias e pensamentos. Suas atividades são alheias a um departamento excessivamente burocrático, onde tarefas podem ser executadas mecanicamente. Segundo De Masi (2003, p.373) toda máquina organizacional, pensada para produzir objetos e necessidades em série, contrasta com a máquina organizacional e criativa necessária para gerar idéias originais e consolidar o futuro.

A principal questão a ser abordada no presente artigo será o porquê da influência direta do ambiente de trabalho no rendimento de um profissional da área de criação e o quê pode-se fazer para adequar satisfatoriamente, tanto à corporação quanto ao grupo criativo este local que se passam tantas horas, cujo maior desafio é manter o fluxo de idéias constantemente renovado e com qualidade.

Tem como objetivo, esclarecer alguns aspectos da qualidade do ambiente de trabalho e como ele pode afetar especificamente o grupo criativo no ambiente empresarial que necessita de constante renovação de idéias e estímulos externos para o bom desenvolvimento de seu trabalho. Segundo (FARIA; ALENCAR, 1996, p.50) a criatividade é passível de desenvolvimento e necessita de determinadas condições para poder se 
manifestar, dentre elas, fatores de natureza sócio-cultural e os atributos de personalidade, tais fatores atuam de forma integrada e interativa.

\section{Fundamentação teórica}

A questão da criatividade tem sido abordada e estudada cada vez mais devido a sua grande importância na sociedade pós-industrial. Com o domínio de técnicas informatizadas que substituem o trabalho braçal, se faz necessário entender sob aspecto psicológico, social e cultural o processo criativo.

Serão abordados a seguir os aspectos relevantes à aplicação do estudo proposto, como o entendimento da criatividade sob o aspecto psico-social, como funciona o indivíduo e o grupo, quais estímulos podem ser oferecidos para que isso se desenvolva e flua com mais naturalidade, alguns conceitos ergonomia e de qualidade.

\section{Aspectos psicológicos associados à ambientes criativos}

Segundo Birman (2008, p.12) o psicanalista Donald W. Winnicott, em publicação da década de 70 em um de seus artigos sobre a criatividade, afirma que a experiência cultural havia sido negligenciada no desenvolvimento psíquico pela comunidade psicanalítica. "A experiência cultural não encontrou o seu verdadeiro lugar na teoria utilizada pelos analistas em seu trabalho e em seu pensar" (apud BIRMAN, 2008, p.12).

São inúmeras as contribuições de autores psicanalistas, psicólogos e sociólogos sobre o assunto, utilizando aqui a linha de raciocínio onde todo indivíduo possui sua parcela de criatividade, que pode ou não desenvolver-se mais ou menos de acordo com os estímulos, desenvolvimento e relação com a realidade interna e externa de cada ser, todos usam de alguma forma a criatividade para ao menos criar sua própria personalidade.

Alencar (1998, p.19) salienta que em décadas de pesquisas sobre o tema criatividade, tem-se apontado cada vez mais para fatores que influenciam a criatividade positiva ou negativamente nos ambientes das organizações, como também elementos pessoais favoráveis e desfavoráveis a sua expressão. A criatividade se desenvolve com mais facilidade nos indivíduos que realizam tarefas, mobilizados pelo prazer e satisfação do que pela obrigação.

A cultura é crucial para a constituição da subjetividade, que veio em contrapartida à massificação imposta pelo início da era industrial, onde produtos de série industrial teriam que ser de mesmo modelo estético pelos motivos produtivos e o consumismo destes bens seria uma inserção à era da modernidade. Entretanto, com o avanço da tecnologia as empresas iniciaram o processo de diversificação, onde surgiram ofertas diferenciadas e os consumidores em busca de uma identidade própria responderam a essa demanda exigindo cada vez mais das organizações.

Para Rivlin (2003, p.216) a psicologia ambiental pode ser explicada por dois pontos inter-relacionados. O primeiro é o papel do ambiente na oferta de imagens do passado, presente e possivelmente do futuro, algumas de natureza agradável e outras desafiadoras. Desta maneira entende-se que o ambiente é um complexo com o qual as pessoas estão integradas e que provem ordem, desordem e diversidade. O segundo ponto lida com o fato das constantes mudanças no ambiente, como novas tecnologias, ameaças naturais ou não as quais levam à necessidade de um ambiente de sobrevivência. 
O autor também salienta que não apenas o ambiente exerce influencia sobre o indivíduo, mas o indivíduo provoca reações no meio. Ele cita alguns pressupostos que oferecem uma visão geral da experiência ambiental, vale destacar alguns: O ambiente frequentemente opera abaixo do nível de consciência, tomando a mesma somente quando algo muda e é preciso adaptar-se a isso; $\mathrm{O}$ ambiente tem valor simbólico, proporcionando o poder de conectar as pessoas com lugares de seu apego, evocando sentimentos positivos ou negativos.

No ambiente que cerca um ser humano, deve existir acesso à cultura, informação, incentivo a brincadeiras, leituras, jogos que estimulem a criatividade e a curiosidade pelo novo. Trabalhar a mente de maneira que haja cada vez mais interação com o meio e por uma melhora do coletivo, ter sempre um pensamento voltado para o aprimoramento das idéias e sua execução.

A fim de entender as reais necessidades de um grupo, é necessário estudar seu funcionamento de maneira geral. Como se comportam pessoas com este perfil, como se comunicam, quais os conceitos de qualidade e como um bom projeto pode facilitar o funcionamento de departamento e direcionar seus usuários.

\section{Criatividade}

De Masi (2003) explica no livro Criatividade e Grupos Criativos como a criatividade evoluiu e sempre esteve presente na história da humanidade. É bem nítida a influência do contexto histórico-social de cada época. Passa pelos Homo habilis, erectus e sapiens, Homens das Cavernas, Sociedade Rural até a Sociedade Industrial para explicar a oscilação do prazer associado ou não ao trabalho, cita as diferenças e conseqüências das evoluções tecnológicas que criaram necessidades específicas de mercado e justifica a crescente preocupação em manter na sociedade indivíduos criativos.

A sociedade pós-moderna em que se vive hoje, ainda sofre resquícios da sociedade industrial, como a jornada de trabalho bem específica, o que acaba por delimitar nosso tempo livre, em contrapartida o homem está cada vez mais preocupado com seu bem-estar, convívio harmônico, busca por crescimento intelectual, visando empregos que exijam cada vez menos esforços físicos e melhor remuneração visando o aumento da qualidade de vida.

É sabido também que para o alcance de melhoras de emprego, se faz necessário o investimento na cultura, fazendo com que a disseminação da educação seja valorizada e o indivíduo tente se diferenciar pelo seu potencial intelectual criativo, valorizando-se e exigindo cada vez mais das organizações, que por sua vez começam a entender e precisar de profissionais mais qualificados, flexíveis e criativos, a fim de sobreviverem no mercado mais e mais competitivo.

De Masi (2000, p.149) afirma que das atividades intelectuais que se destacam na sociedade pós-industrial, a mais apreciada é a criatividade com a estética também em evidência, pois ao alcançar a perfeição tecnológica nos produtos manufaturados nos resta o refinamento estético destes. Em contrapartida da excessiva racionalização que permite executar tarefas, a emotividade está voltando a ser valorizada, pois sem ela, não se cria nada novo. Emoção, fantasia, racionalidade e concretude são os ingredientes da criatividade.

Ainda segundo o autor acima, a criatividade pode ser dividida em algumas categorias, o psicólogo Harold $\mathrm{H}$. reconhece a criatividade social como a criatividade que se exerce nas pessoas, através do relacionamento, respeito ao indivíduo, sensibilidade, inteligência e percepção. É a criatividade que estabelece um bem estar geral, voltado a produtos não 
tangíveis para melhora da qualidade de vida dos seres. As outras formas de criatividade são artística, científica, inventiva, ordinária e extraordinária.

É relativamente comum ouvir algumas pessoas dizerem que são ou não criativas, como se isso fosse uma característica imutável e estivesse definida geneticamente. Para muitos pesquisadores da psicologia antiga essa era uma explicação plausível, visto que levavam em conta a criatividade extrema como dos grandes gênios e não tomavam por base as pequenas invenções diárias que auxiliavam no cotidiano.

Entender as características comportamentais e de pensamento destes considerados criativos e cada vez mais reconhecidos como indivíduos que podem trazer, a longo prazo, o sucesso para o empreendimento devido sua flexibilidade, capacidade de aceitar o novo e a partir do usual conceber uma outra utilidade ou olhar, gerando assim inovação.

Para Gomes (1994, p.57) o homem criativo foge ao convencional, e carrega em sua marca uma pitada de subversão das coisas estabelecidas e sua imaginação está em constante processo de fermentação, já Guinford (1950, p. 450) identificou que o pensamento divergente, que se distingue, sobretudo pela riqueza e originalidade das idéias é um dos componentes do intelecto do indivíduo criativo.

Entretanto, estudos mostram que a criatividade não é benefício ou uma graça obtida e destinada a alguns seres supremos, ela pode e deve ser desenvolvida, estimulada e influenciada pelo ambiente que os cercam "devemos abandonar a visão Ptolomênica da criatividade na qual a pessoa está no centro de tudo, para um modelo similar ao de Copérnico, no qual a pessoa é parte de um sistema de mútuas influências e informações" (apud ALENCAR, 1998, p.19).

A autora destaca traços de personalidade observadas em profissionais de produção criativa a pró-atividade, pensamento coletivo, flexibilidade de pensamentos e atitudes, pensamento divergente, persistência e disposição para correr riscos previamente estudados e entendidos através de experiências e bagagem de conhecimento. Além destas, aponta que as organizações por sua vez, devem através de seus líderes, cultivarem um ambiente de abertura e apoio às idéias inovadoras.

A criatividade é um processo metal complexo, que depende de vários fatores individuais, externos e principalmente do coletivo e só evolui do campo da idéia a partir do momento em que o indivíduo ou grupo consegue concretizá-la.

\title{
Coletividade
}

\begin{abstract}
Não podemos falar da "pessoa criativa"; podemos falar apenas do "ato criativo", porque o que ocorre é sempre um processo, uma ação; especificamente, um processo que põe em relação a pessoa e o seu mundo (apud DE MASI, 2003, p.481).
\end{abstract}

Todo tipo de organização é constituída de grupos de pessoas, é necessário que estas se relacionem de maneira harmônica para o crescimento de um todo. Os grupos criativos podem ou não ser formados por indivíduos interdisciplinares. Considerando que todos os membros do grupo são criativos, a flexibilidade de aceitar idéias e se adaptar ao modo de trabalho se torna mais fácil e a interdisciplinaridade agrega valores e possibilidades ao produto desejado.

Mesmo que a criatividade passe por ciclos mais ou menos férteis, quando trabalhado em grupo, é mais difícil que os indivíduos estejam em mesmo período, isso ajuda a 
estabelecer um certo ritmo contínuo, pois as idéias se aprimoram e o autor da mesma já não se sente realizado em ajudar o coletivo e não tem o interesse em centralizar a produção.

Dos fatos históricos citados por De Masi em abordagem ao assunto de criatividade, está sempre presente a questão do grupo, da coletividade.

Na criatividade de grupo, justamente pela própria natureza da atividade coletiva, não são apenas a qualidade dos membros individuais que incidem sobre os processos ou sobre os produtos, quanto melhor for a interação entre os membros do grupo, melhor será entre o grupo e o mundo exterior. (DE MASI, 2003, p.480).

O grupo de maneira geral é formado por indivíduos com o mesmo ou muito semelhante perfil, todos possuem uma boa bagagem cultural, informações atualizadas, são flexíveis e a questão da priorização do crescimento do grupo antes do crescimento individual. Desta maneira é possível manter a homogeneidade e bom relacionamento entre as partes. Cada um se garante por sua vez pela contribuição, confiança no seu bom desempenho e a vontade de aprimorar-se cada vez mais.

Manter esses grupos unidos e eficazes faz parte da estrutura organizacional, para isto é importante conceber tais condições e reciclar seus colaboradores oferecendo treinamentos, viagens e constante liberdade de criação.

\section{Estímulos externos}

A criatividade está ligada ao sentimento de liberdade de expressão, ter um ambiente que reprima tal instinto certamente irá reduzir a produtividade do grupo, é necessário que se tenha interação sem tirar a privacidade do momento criativo, respeitar certos ciclos para que o criador não se sinta pressionado ou limitado a mesmice.

Tais estímulos externos não devem ser levados em consideração apenas o material, o palpável, mas também as características intangíveis que somente são percebidas e não temos medidores, são as relações interpessoais que geram sensações e influenciam diretamente o comportamento de uma empresa.

\section{A importância da ambientação - Design de interiores}

Os lugares físicos nos quais se trabalha, os homens e as mulheres com os quais colaboramos, os líderes que nos guiam, a cultura que nos intriga e as gratificações que nos lisonjeiam fazem parte, em grande medida, de um mundo ainda hoje baseado na serialidade e na capacidade de execução, em valores de obediência, de conformidade e de prescrições. (DE MASI, 2003, p.373)

Um projeto de interiores sempre considera a estrutura do edifício, sua localização, o contexto social, legislação de uso e o respeito ao meio ambiente. A criação exige uma metodologia sistemática e coordenada que incluem pesquisa e levantamento das necessidades do cliente, sua adequação às soluções estruturais e de sistemas e produtos.

Muitas variáveis influenciam um projeto de interiores na busca de soluções tanto criativas quanto técnicas que proporcionem qualidade de vida e cultura para os seus usuários sempre relacionando qualidade estética e funcional. A mais importante refere-se à natureza do seu uso: trabalho, lazer, tratamento, estudo ou morar, que determina a maneira de pensar do projetista, pode-se também associar aos fatores práticos como acessibilidade, conforto térmico e acústico, iluminação e espaço de armazenamento adequado, mas todas 
essas variáveis sempre são voltadas às questões fundamentais de saúde, conforto, segurança e durabilidade.

São muitos os fatores que podem estimular ou barrar a criatividade, serão tratados aqui somente os estímulos, que segundo Faia e Alencar (1996), em estudo sobre Estímulos e barreiras à criatividade no ambiente de trabalho, listam doze aspectos relevantes: Ambiente físico (espaço físico, circulação, iluminação, mobiliário, silêncio e temperatura adequada); Comunicação (informações democratizadas, claras, objetivas e disponíveis); Desafios (estimulam a expressão do potencial criador, consideram importante o trabalho que realizam); Estrutura organizacional (normas flexíveis, redução de hierarquia e burocracia); Liberdade e autonomia; Participação (em tomada de decisões e solução de problemas); Recursos tecnológico e materiais; Salário e benefícios; Suporte da chefia (receptividade, flexibilidade, aceitação e respeito às opiniões divergentes).

Para Gomes (1994, p.80) o ambiente é influenciado pela cultura e diversos fatores sociais, de modo que seu design deve refletir o nível de vida dos usuários. O sucesso depende, entre outras coisas, de um projeto bem-concebido, no qual se devem considerar todos os aspectos relativos às necessidades do colaborador. Para ela a música ambiente pode influenciar no humor, ativando o processamento cerebral com reações emocionais correspondentes, assim como os aromas não são fundamentais para o bom funcionamento do local, mas ajudam a melhorar a atmosfera.

As cores sofrem inúmeras descrições de sensações e a utilização desde Feng shui a Semiótica, há uma discrepância entre seus efeitos e sua escolha não deve se ater apenas ao teórico, mas também propiciar aos principais interessados a sensação agradável de ter um ambiente renovado com cores leves e que condizem com o contexto da organização e do grupo.

\section{Ergonomia}

A ergonomia é uma ciência multidisciplinar que estuda o ser humano e seu espaço físico e organizacional, envolvendo medidas, funcionamento, funções e usabilidades, sendo estas utilizadas por profissionais das áreas de Fisioterapia, Design, Arquitetura, Psicologia e Engenharia de Produção.

Couto (1995) diz que a ergonomia se baseia em um conjunto de ciências e tecnologias que enfatiza a adaptação confortável e produtiva entre o ser humano e seu trabalho, tentando adaptar as condições de trabalho às características do ser humano.

Para Wisner (1987) a Ergonomia se baseia em um conjunto de conhecimentos científicos relacionados ao homem que são necessários para conceber instrumentos, máquinas e dispositivos que devem ser usados com o máximo de conforto, segurança e eficácia por seus usuários.

lida (1990) diz que a Ergonomia não estuda apenas a adaptação do homem a máquinas e equipamentos, mas todo o processo que ocorre durante o relacionamento do homem e seu trabalho. O autor destaca como uma concisa definição de Ergonomia a da Ergonomics Research Society, Inglaterra (Sociedade de Pesquisas Ergonômicas, Inglaterra):

Ergonomia é o relacionamento entre o homem e o seu trabalho, equipamento e ambiente, e particularmente a aplicação dos conhecimentos de anatomia, fisiologia e psicologia na solução de problemas surgidos desse relacionamento. 

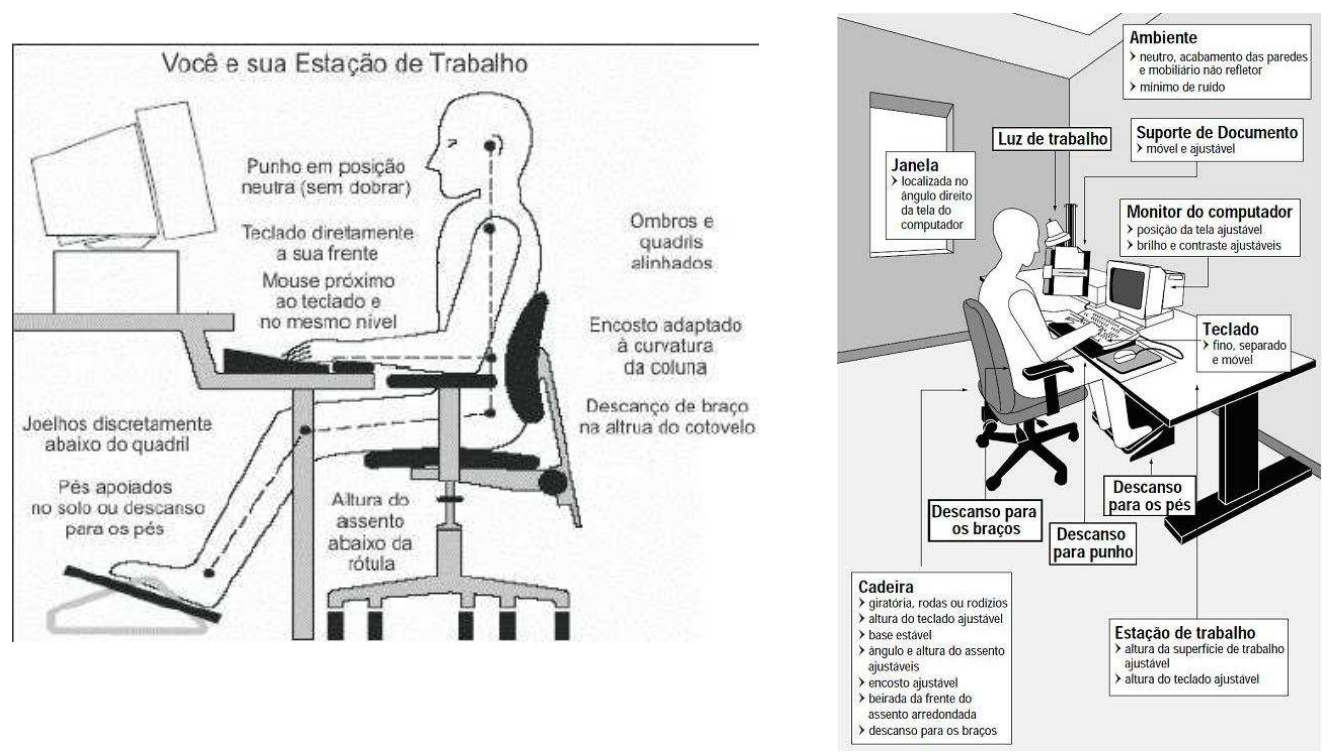

Figura 1 e 2 - Representações ergonômicas. Fonte: Abergo (2010).

O corpo tem suas necessidades de acomodações, seja em trabalhos na posição em pé ou sentado, trabalhos que usem muito ou menos as mãos, os pés e os olhos devem ser realizados de maneira a causar o mínimo de impacto possível ao trabalhador. Como cita Guérin (2001), a análise do modo de executar o trabalho contribui para identificação dos mecanismos de agressão à saúde ligados a este, afim de preveni-los por uma transformação dos meios deste.

Segundo Dul e Weerdmeester (1995), a altura da superfície de trabalho deve ser ajustável entre 54 e $79 \mathrm{~cm}$, com uma faixa de $25 \mathrm{~cm}$ para acomodar as diferenças individuais. No caso de manipulação de peças de diferentes alturas, a faixa de ajustes deve ser ainda maior. De preferência, essa altura deve ser facilmente regulável, a partir da posição sentada.

Tabela 1. Recomendações gerais para a altura da superfície de trabalho.

\begin{tabular}{|l|c|}
\hline \multicolumn{1}{|c|}{ Tipo de tarefa } & Altura da superfície de trabalho \\
\hline $\begin{array}{l}\text { Uso dos olhos: muito Uso } \\
\text { das mãos e braços: pouco }\end{array}$ & 10 a $30 \mathrm{~cm}$ abaixo da altura dos olhos \\
\hline $\begin{array}{l}\text { Uso dos olhos: muito Uso } \\
\text { das mãos e braços: muito }\end{array}$ & 0 a $15 \mathrm{~cm}$ acima da altura do cotovelo \\
\hline $\begin{array}{l}\text { Uso dos olhos: pouco Uso } \\
\text { das mãos e braços: muito }\end{array}$ & 0 a $30 \mathrm{~cm}$ acima da altura do cotovelo \\
\hline
\end{tabular}

Fonte: Dul e Weerdmeester (1995).

Um dos principais objetivos ao se implantar a gestão do design em uma organização é melhorar o seu desempenho em relação à qualidade de serviços prestados e produtos, desde sua criação até sua produção final, pode-se conseguir tais melhorias através de propostas ergonômicas amigáveis aos usuários (LINDEN, 2007). 


\section{Qualidade}

A globalização quebrou barreiras físicas e aproximou os povos, aumentou a lei da oferta e procura por produtos que se aperfeiçoam aos usos e aos usuários. Para que se tenha sucesso na oferta de um produto ou serviço a qualidade entra como requisito básico da sobrevivência no mercado.

Os conceitos de qualidade são os mais variados, de acordo com o enfoque mercadológico, mas de maneira geral é o grau no qual um conjunto de características permanentes satisfaz e atende as necessidades específicas ou implícitas (ZACHARIAS, 2009, p.30).

A qualidade depende da exigência e expectativas sobre um produto ou serviço, podendo variar seus conceitos e definições, segundo Garvin (1992), existem cinco abordagens para sua conceituação: Transcendental, baseada no produto, baseada no usuário, baseada na produção e baseada no valor embora todas entendam que para se ter qualidade não se pode simplesmente atender às necessidades, mas sim superar expectativas e constante monitoramento das atividades.

Para Spiller (2006, p.96) as dicas de manter a cultura da qualidade são: buscar a perfeição, acreditando que é possível fazer certo da primeira vez; difundir internamente essa crença; recompensar os funcionários; busca de aprimoramento contínuo; estar em sintonia com o consumidor, conhecendo suas demandas, interesses, expectativas e problemas.

\section{Qualidade do ambiente de trabalho}

O ambiente de trabalho somente é propício quando se entende o seu uso e este é aprimorado à funcionalidade e conforto dos usuários. Tal ambiente, seja ele físico ou todos os fatores que cercam o indivíduo, precisa estar adequado para seu correto funcionamento. No caso de departamentos de criação, precisa além dos requisitos básico de ergonomia, iluminação e ventilação dar estímulos aos seus usuários, a fim de deixá-los mais confortáveis e proporcionar a interação necessária que este grupo necessita para o desenvolvimento de seu trabalho.

Mesmo com a internet e informações virtuais que se tem acesso, é importante ter um material palpável para consultas, abastecimento e reciclagem de idéias, portanto se faz necessária armazenagem destes materiais que são muito consultados e o estudo da melhor maneira de acomodá-los.

Assim como o ambiente físico é importante, as condições de trabalho no que diz respeito ao entendimento do processo, metas, clareza de funções e contribuições, liberdade de experimentos, críticas construtivas e interação entre departamentos e gerência, boas relações interpessoais, se fazem fundamental para estes profissionais que respondem a estímulos externos para processarem sua capacidade criativa.

Alencar (1998, p. 24) destaca cinco principais maneiras de se alcançar o ambiente ideal para a criatividade, sendo elas: Comprometimento com as metas que deve ser permanentemente alimentado; Cultivo da cultura da flexibilidade, comunicação, desafio, prazer e sentimentos de pertencimento; incentivos e prêmios às novas idéias e produção criativa; processo permanente de renovação; treinamento de funcionários para o desenvolvimento de projetos. 
Qualidade na execução de tarefas

O sentido da vida em grupo é o que permeia a nova cultura de prevenção nas
empresas. É evidente que se trata de uma filosofia, e não técnicas. O mundo real
não vive dependendo de siglas. Existe uma grande confusão de métodos e nomes.
No entanto todos eles revelam a pista da integração entre as pessoas com o
sistema, para viabilizar a qualidade no sentido mais amplo da palavra. (GOMES,
1994, p. 23)

A palavra cliente não pode ser vista unicamente como o usuário final de um produto ou serviço, dentro de uma organização existem vários clientes, devido ao trabalho cíclico. 0 trabalho executado por um departamento seguramente passa a outro departamento antes de atingir o consumidor final. O meu cliente passa a ser o próximo departamento que irá trabalhar neste produto, pensando desta maneira é indispensável atender as suas necessidades, sejam elas de entendimento de processos, clareza de execução, etc. para Gomes $(1994$, p. 6) toda organização é um organismo vivo que requer um clima saudável e que necessita de constante crescimento e aprimoramento de idéias e isto só será possível através da integração da comunicação e do relacionamento.

Junto ao produto, deve constar sua explicação técnica clara e funcional para que o trabalho do setor adiante possa ser realizado na perfeita ordem. Aqui é importante lembrar que um retorno com críticas construtivas e ou elogios, fornece dados importantes aos realizadores da tarefa anterior, pois somente desta maneira poderão avaliar seu desempenho e melhorar falhas para o próximo produto.

Segundo Costa (1999, p. 28) o questionamento periódico e o pensamento do melhoramento contínuo fazem parte do acompanhamento das reformulações das necessidades e percepção das pessoas. Para o departamento é fundamental manter um histórico detalhado das ações, documentando o antes, durante e depois de uma entrega de produto. Com isso há o monitoramento constante sobre as tarefas e executores das mesmas.

\section{Metodologia de Pesquisa}

Por meio da observação da qualidade do rendimento de um grupo criativo inserido no ambiente de trabalho empresarial excessivamente formal e da diferença entre os grupos de trabalho, pôde-se notar a necessidade de explicações, mais a fundo, sobre a influência direta no comportamento da equipe criativa e seu posto de trabalho.

Trata-se de um trabalho exploratório de abordagem qualitativa, que segundo Minayo (1999) visando o exame detalhado de uma situação particular, entretanto não pretende o alcance absoluto da verdade, preocupa-se primeiramente à preocupação da lógica que permeia a prática que se dá na realidade.

Realizado a partir da observação da rotina de trabalho de um grupo de dez pessoas, conforme Tabela 2, em qu nove destas trabalham de maneira tradicionalmente empresarial: oito horas de trabalho por dia, cinco dias na semana, com horário de almoço de uma hora e meia e outra trabalha como assessora de assuntos de criação, por ter um amplo conhecimento de mercado e contato direto com consumidores considerados o público-alvo desta empresa. 
Tabela 2. Descrição de cargos x jornada de trabalho

\begin{tabular}{|c|c|c|c|}
\hline indivíduos & gênero & cargo & jornada de trabalho \\
\hline 1 & $q$ & arquiteta & 8hs semanais \\
\hline 2 & $q$ & arquiteta & 30hs semanais \\
\hline 3 & $q$ & marketing & 40hs semamais \\
\hline 4 & $q$ & comercial & 40hs semamais \\
\hline 5 & $q$ & comercial & 40hs semamais \\
\hline 6 & 0 & marketing & 40hs semamais \\
\hline 7 & $\hat{0}$ & projetista & 40hs semamais \\
\hline 8 & 0 & projetista & 40hs semamais \\
\hline 9 & 0 & projetista & 40hs semamais \\
\hline 10 & $\hat{0}$ & web designer & 40hs semamais \\
\hline
\end{tabular}

Fonte: Própria.

O primeiro contato foi uma conversa coletiva e informal para levantar as sugestões sobre o ambiente ideal e como agregar qualidade dentro dos recursos disponíveis, a fim de melhorar o local com pequenas intervenções para avaliação de comportamento do grupo em questão, do rendimento e da qualidade de serviço realizado.

Anterior à fase de desenvolvimento do projeto da sala e postos de trabalho da equipe, foram aplicados de maneira individual, dois questionários; o primeiro para saber o nível da qualidade do departamento, onde checou-se quatorze aspectos subdivididos em perguntas mais específicas com respostas enumeradas de 5 (Excepcionalmente boa) a 1 (Totalmente inaceitável). Tais itens foram levantados como relevantes no capítulo 2.3, com o objetivo de avaliar o funcionamento, entendimento e satisfação de seus integrantes sobre o ambiente de trabalho como um todo. Entende-se aqui tal ambiente também pelos aspectos psico-sociais com tarefas, missões, hierarquias, liberdade, participação, etc., e não somente o aspecto físico.

O segundo questionário com perguntas específicas sobre o ambiente físico de trabalho em relação à ergonomia, assim foi elaborado a partir dos problemas levantados e priorizados pela conversa informal com os colaboradores do departamento, resultando em duas questões abertas e oito questões referentes ao nível de importância do sujeito em relação ao item questionado, usando com uma escala de avaliação contínua, representada por uma linha de $15 \mathrm{~cm}$ (em escala 1:50) com ponto de partida característico como não importante $(0)$, ponto central neutro $(7,5)$ e ponto final representando a importância $(15)$.

Este questionário foi elaborado visando respostas objetivas para coleta de informações que serviram como briefing na etapa de ante-projeto. Após a aplicação dos questionários realizou-se um brainstorming para que as idéias do grupo pudessem ser melhores avaliadas e devidamente aplicadas no projeto.

\section{Resultado dos questionários}

Esta avaliação se faz importante para iniciar esta pesquisa, pois desta maneira pôdese ter a certeza de como o departamento é visto pelos próprios integrantes e entender seu funcionamento e falhas.

$\mathrm{Na}$ aplicação do primeiro questionário foram abordados quatorze tópicos, sobre: metas estabelecidas, divisão de responsabilidades, eficácia/eficiência e produtividade, 
tomada de decisões, delegação, comunicação e coordenação internas, comunicação e coordenação externas, ambiente físico, consciência da qualidade, criatividade e inovação, comprometimento, reconhecimento e recompensa, desenvolvimento de funcionários e ambiente psicológico em geral (COSTA, 1999), conforme mostra a Tabela 3.

Tabela 3 - Resultado questionário 1 - Qualidade do departamento.

\begin{tabular}{|c|c|c|c|c|c|c|}
\hline № & Como você avalia a qualidade departamental nesta área? & 5 & 4 & 3 & 2 & 1 \\
\hline \multirow[t]{5}{*}{1} & Metas & & & & & \\
\hline & As metas departamentais são claras? & & & $x$ & & \\
\hline & Todos as conhecem? & & $x$ & & & \\
\hline & Elas são realistas e desafiantes? & & & $x$ & & \\
\hline & São aceitas por todos? & & $x$ & & & \\
\hline \multirow[t]{4}{*}{2} & Divisão de responsabilidades & & & & & \\
\hline & $\begin{array}{l}\text { Todos sabem exatamente pelo que são responsáveis e o que é deles } \\
\text { esperado? }\end{array}$ & & $x$ & & & \\
\hline & Todos sabem o que pode ser feito sem perguntar antes? & & & & $x$ & \\
\hline & Cada pessoa entende seu papel geral das coisas? & & & $x$ & & \\
\hline \multirow[t]{4}{*}{3} & Eficácia/ Eficiência/ Produtividade & & & & & \\
\hline & $\begin{array}{l}\text { O departamento satisfaz as expectativas dos outros quanto à eficácia e à } \\
\text { produtividade? }\end{array}$ & & & $x$ & & \\
\hline & $\begin{array}{l}\text { As coisas são sempre feitas em tempo, com a qualidade acertada e o uso } \\
\text { mínimo de recursos? }\end{array}$ & & & $x$ & & \\
\hline & Sua porcentagem de erros é aceitável? & & & $x$ & & \\
\hline \multirow[t]{4}{*}{4} & Tomada de decisões & & & & & \\
\hline & As decisões no departamento são tomadas em um nível sensato? & & & $x$ & & \\
\hline & As decisões são tomadas com a rapidez necessária? & & $x$ & & & \\
\hline & Elas se baseiam em informações suficientes? & & & & $x$ & \\
\hline \multirow[t]{5}{*}{5} & Delegação & & & & & \\
\hline & Existe suficiente delegação? & & $x$ & & & \\
\hline & As habilidades dos funcionários são bem utilizadas? & & & & $x$ & \\
\hline & O método de delegação é sensato? & & & $x$ & & \\
\hline & $\begin{array}{l}\text { Os funcionários estão sendo treinados para aceitar responsabilidades cada } \\
\text { vez maiores? }\end{array}$ & & & $x$ & & \\
\hline \multirow[t]{8}{*}{6} & Comunicação e Coordenações internas & & & & & \\
\hline & Funcionamos como uma equipe? & & $x$ & & & \\
\hline & Estamos todos puxando na mesma direção? & & $x$ & & & \\
\hline & Mantemo-nos mutuamente bem informados? & & & $x$ & & \\
\hline & Nossos métodos de comunicação são adequados? & & & $x$ & & \\
\hline & Fazemos reuniões eficazes? & & & $x$ & & \\
\hline & Contatamos uns aos outros quando podemos ser contatados? & & & $x$ & & \\
\hline & Mostramos respeito pelo tempo alheio? & & $x$ & & & \\
\hline \multirow[t]{2}{*}{7} & Comunicação e Coordenações externas & & & & & \\
\hline & Trabalhamos bem com outros departamentos? & & $x$ & & & \\
\hline
\end{tabular}


O departamento sabe quais são seus "clientes"?

O departamento sabe o que os clientes esperam deles?

O fluxo de informações interdepartamentais é adequado e sensato?

\section{Ambiente Físico}

O bem-estar e a eficiência do departamento são ampliadas pelo ambiente físico?

Edifícios e escritórios

Decoração e projeto

Ampliado

lluminação

Nível de ruído

Ventilação

Equipamentos e materiais

Levamos a qualidade a sério?

Sabemos quais são nossos fatores de qualidade?

Existem metas claras de qualidade para todas as funções, produtos e atividades?

Avaliamos regularmente a adequação de nossas ações?

Encaramos o elo seguinte na cadeia como um valioso cliente?

Fazemos pleno uso de nossos recursos?

Verificamos a qualidade de nosso trabalho?

Exigimos qualidade uns dos outros e daqueles que nos cercam?

Criatividade e Inovação

Estamos conscientes de todos os acontecimentos à nossa volta?

Todos entendem a necessidade de mudanças?

Somos suficientemente flexíveis?

Estamos dispostos a nos adaptar?

Começamos a usar novas tecnologias?

Usamos técnicas criativas?

Comprometimento

Fazemos o melhor que podemos?

Cumprimos nossos acordos?

Todos trabalham para promover melhoramentos e desenvolvimentos?

Todos estão dispostos a fazer um esforço extra, quando a situação assim $x$ exige?

Todos vêem um desafio em cada função e ação?

12 Reconhecimento e Recompensas 


\begin{tabular}{|c|c|c|c|c|c|}
\hline & Os bons resultados são tomados "visíveis"? & & & $x$ & \\
\hline & O desempenho de qualidade é recompensado? & & & $x$ & \\
\hline & $\begin{array}{l}\text { As realizações de primeira classe aumentam as chances de promoção e } \\
\text { desenvolvimento? }\end{array}$ & & & & \\
\hline & $\begin{array}{l}\text { A gerência focaliza mais de perto os pontos fortes dos funcionários do que os } \\
\text { pontos fracos? }\end{array}$ & & & $x$ & \\
\hline & $\begin{array}{l}\text { Existem grupos de funcionários que nunca recebem atenção e } \\
\text { reconhecimento? }\end{array}$ & & & $x$ & \\
\hline & $\begin{array}{l}\text { Quando um funcionário é chamado pelo chefe, geralmente espera ser } \\
\text { elogiado e não criticado? }\end{array}$ & & & $x$ & \\
\hline 13 & Desenvolvimento de funcionários & & & & \\
\hline & Os funcionários são encorajados para que se desenvolvam? & & $x$ & & \\
\hline & Existe um plano para o desenvolvimento individual dos funcionários? & & & & \\
\hline & Existem boas oportunidades educacionais? & & & $x$ & \\
\hline & O treinamento é pago pela empresa? & & $x$ & & \\
\hline & É possível fazer rotação, variação e promoção de cargos? & & & & \\
\hline & Os funcionários recebem desafios razoáveis? & & & $x$ & \\
\hline 14 & Ambiente Psicológico em Geral & & & & \\
\hline & Nós nos divertimos trabalhando juntos? & $x$ & & & \\
\hline & Temos prazer em vir trabalhar todos os dias? & & $\mathrm{x}$ & & \\
\hline & Sentimo-nos seguros em nossos empregos? & & & $x$ & \\
\hline & Nós nos ajudamos e encorajamos mutuamente? & & $\mathrm{x}$ & & \\
\hline & Confiamos uns nos outros? & $\mathrm{x}$ & & & \\
\hline & Nossa comunicação é aberta e honesta? & & & $x$ & \\
\hline & Falamos uns com os outros e não dos outros? & & & $x$ & \\
\hline & Respeitamos as habilidades, os desejos e a individualidade dos outros? & & $x$ & & \\
\hline
\end{tabular}

\section{Fonte: Própria.}

O questionário seguinte teve como resultado o peso de sua resposta obtida pela média aritmética dos valores assinalados pelos colaboradores.

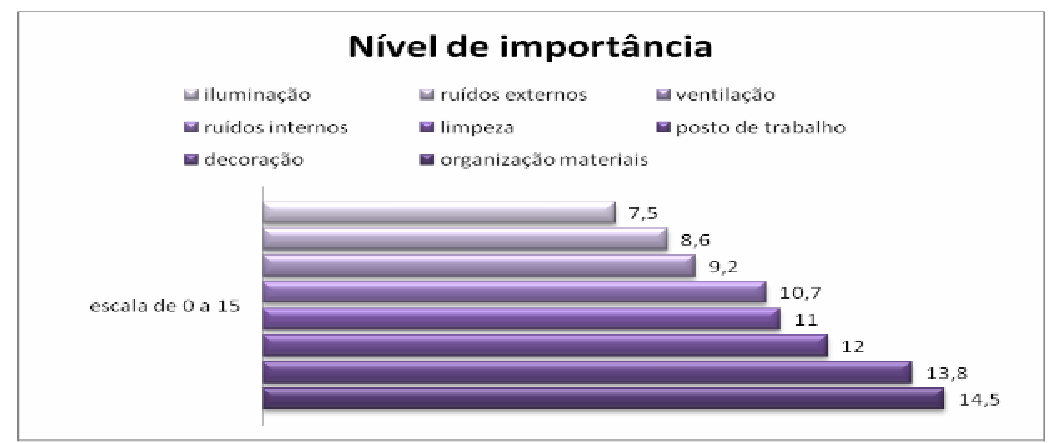

Figura 3 - Resultado questionário 2 - nível de importância dos elementos. Fonte: Própria. 
O terceiro e último contato a respeito dos pontos a serem trabalhados nos projeto foram obtidos através de brainstorming, em que foi possível detectar que a ergonomia do posto de trabalho sempre foi bem atendida e avaliada periodicamente por profissionais competentes e o que de fato incomodava eram: decoração, pintura, falta de ornamentos, até mesmo de música ambiente e aromatizador.

\section{Problemas comportamentais}

Pela análise das respostas do primeiro questionário obteve-se os seguintes resultados: Metas; produtividade, comunicação interna e externa; inovação; comprometimento e ambiente psicológico tiveram notas acima do razoável, o que nos sugere apenas o aprimoramento e continuidade do comportamento adotado até então.

Já os aspectos ligados a valorização do funcionário como: Responsabilidade, decisões, delegação, ambiente físico, qualidade, reconhecimento e desenvolvimentos dos funcionários possuem notas insatisfatórias, sendo o item de reconhecimento e recompensas o que apresentou maiores dificuldades, pois envolve diretamente a questão da gerência e diretoria.

\section{Problemas físicos}

A partir do gráfico referente ao segundo questionário, nota-se que os pontos a serem trabalhados no ambiente físico são bastante importantes na visão dos usuários deste departamento. Portanto, estes tópicos foram bem analisados e colocados em prática na aplicação.

Alguns dos itens não receberam o devido tratamento devido as limitações da edificação ou por ser dada prioridade a outro fator que impedia o favorecimento de ambos. Estes detalhes serão explicados com mais profundidade nos resultados.

O mobiliário na questão ergonômica apesar de sua extrema importância, não foi mencionado em nenhum momento como problema, pois a empresa fornece todos os requisitos necessários para o correto posicionamento para execução do trabalho, incluindo ginástica laboral e avaliações constantes de seus funcionários e seus postos.

\section{Solução}

Após análise da qualidade do ambiente de trabalho, foram propostas melhorias no ambiente físico para que, aos poucos, sejam aceitas e entendidas as diferenças entre esses indivíduos. A empresa concedeu nova sala, com ampliação de espaço e junção do departamento comercial, projetos e marketing cujas funções estão interligadas, melhorando assim a comunicação e interação com os companheiros de trabalho.

Salienta-se aqui que o espaço cedido depende de limitações físicas de uma organização empresarial que ainda comporta outros departamentos e trabalha dentro de um determinado limite em relação à gastos.

\section{Melhoria de relacionamento}

Sugere-se reuniões semanais ou quinzenais, para melhoria contínua dos projetos, produtos e até mesmo de relacionamento, fortificando laços e renovando idéias com maior integração dos indivíduos para que eles possam se ajudar mutuamente e que todos estejam 
informados dos acontecimentos como lançamentos, metas, descontinuidade de produção e possam sugerir de maneira colaborativa mudanças e melhorias para o departamento.

Criação de metodologias de trabalho com acesso aberto a todos, como cronograma digital de todas as atividades ligadas ao setor (solicitação de amostras, desenvolvimento de produtos, desenvolvimento e andamento das franquias) possibilitando assim a documentação datada das atividades e com este registro o aprimoramento contínuo das falhas detectadas por meio do mesmo, desta maneira evita-se o desconhecimento de algum processo por parte de algum dos integrantes da equipe, já que o documento pode e deve ser abastecido e acessado por todos, gerando assim maior integração e conhecimento geral do andamento das tarefas.

A comunicação interna foi padronizada para valorização da marca e do comunicado, ficou dividida em categorias de assunto: Reunião (para organizar e mandar a ata); solicitação (de documentos e afins); news (com informativo de lançamentos e notícias) e memorando (informações sobre procedimentos). Anteriormente as comunicações eram feitas isoladamente, sem a padronização e não era dividida em nenhuma categoria de assuntos.

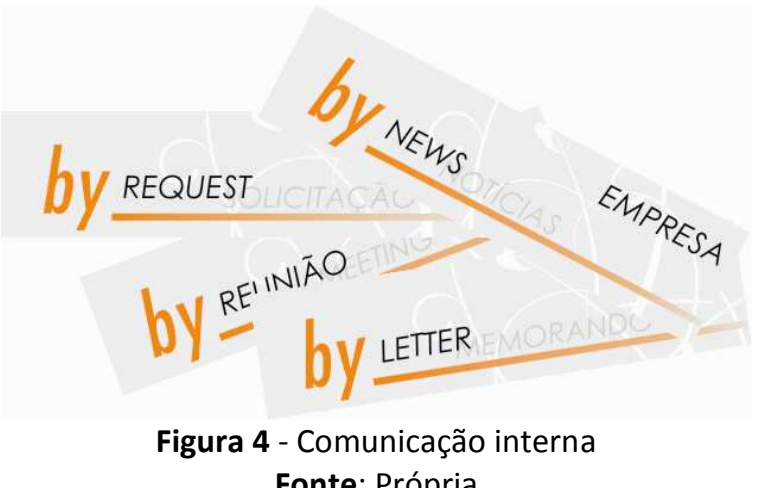

Proposta de melhoria física do departamento

Aqui se juntaram profissionais de outras áreas como tecnologia da informação, designers, arquitetos, fisioterapeutas e administradores para que se elaborasse o layout e os projetos dos postos de trabalho sem problemas ergonômicos e sem limitações tecnológicas.

Foram apresentados dois estudos de layout, em que o primeiro previa uma sala de reuniões, o que inviabilizava a dimensão da bancada de trabalho individual. O segundo estudo, retirada esta sala de reuniões, foi alterado em termos de dimensões de mesa, acréscimo de paredes de isolamento acústico para as impressoras e nesta etapa se determinou o posicionamento de cada indivíduo, visando sempre o bom funcionamento do departamento como um todo. Observa-se na Figura 5 o layout definido. 


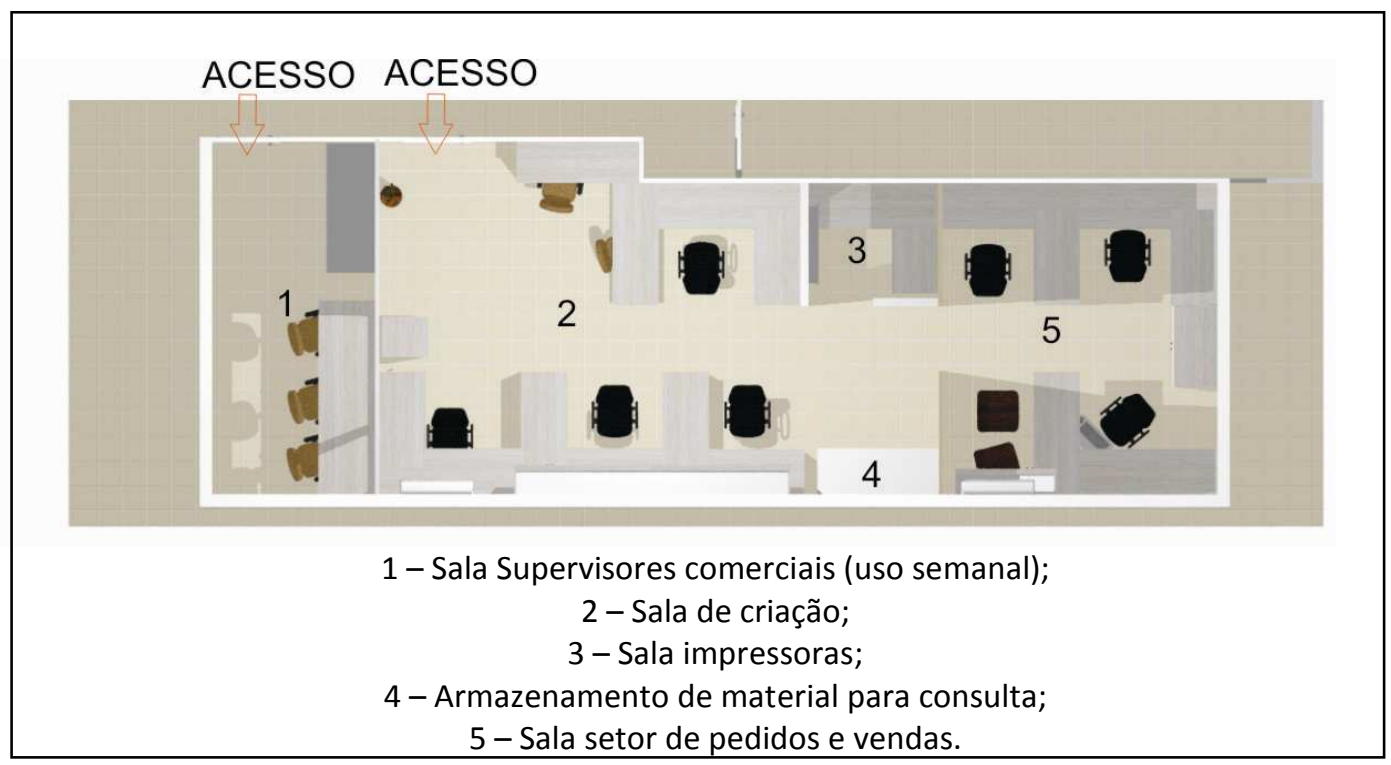

Figura 5 - Layout definido do departamento de criação.

Fonte: Própria.

A análise do layout sugere bancadas de trabalho posicionadas para melhor acomodação dos funcionários, entretanto, foi feito o estudo de comunicação, pois o departamento está em constante debate sobre os mais diversos assuntos, desde criação de anúncios a burocracias de relatórios de pedidos, desta maneira todos podem se posicionar ao centro da sala, formando assim um espaço de discussões para reuniões.

\section{Aplicação}

A partir deste layout inicial se elaborou o projeto detalhado dos móveis, levando em consideração a ergonomia e o estudo de cores. A decoração, item citado como importante para revigorar a criatividade dos usuários, foi pensada nesta fase, com a criação de painel semântico, localização de mapa para facilitar a visualização das lojas parceiras, bem como outros elementos decorativos que receberam seu devido lugar.

O posto de trabalho apresenta dimensões adequadas, o monitor está na altura correta, a cadeira é confortável com regulagem de altura, inclinação, giratória, estofada e possui apoio para os braços, o telefone ao alcance das mãos e apoio para os pés.
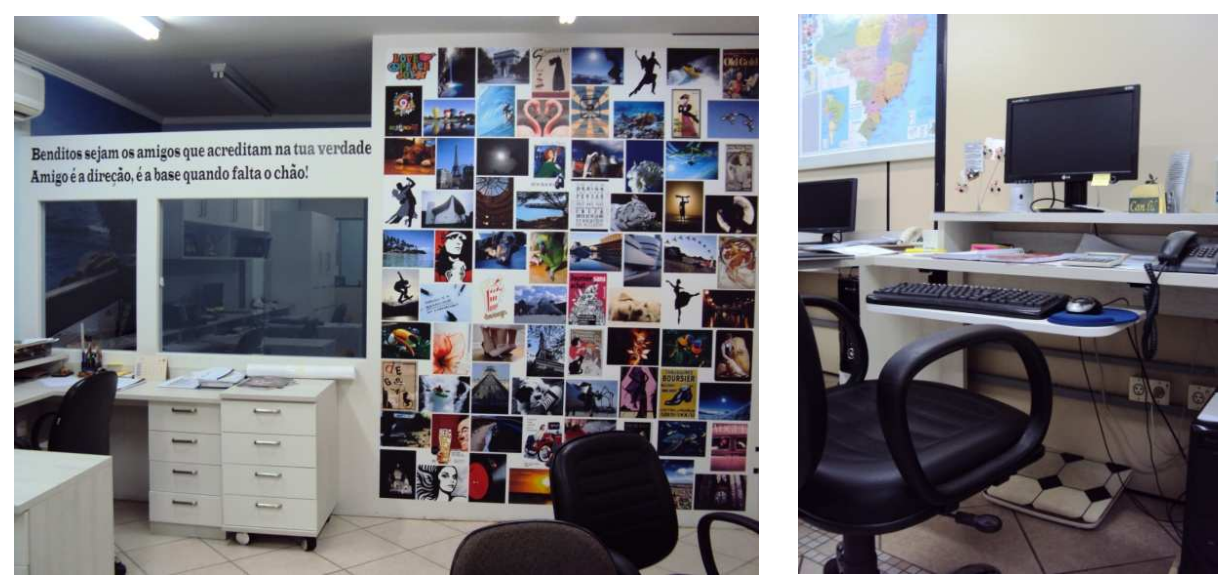

Figura 6 e 7 - Painel semântico e posto de trabalho.

Fonte: Arquivo pessoal. 
Pode-se notar na figura 6 a abertura superior na parede, devido ao ar-condicionado para gerar ventilação para sala dos supervisores e os vidros abaixo com a finalidade de permitir a permeabilidade visual, o que promove maior integração entre os colaboradores.

O painel semântico foi montado focalizando gostos pessoais dos usuários visando a humanização do espaço de trabalho, tais imagens remetem ao aconchego, horas de lazer, sonhos, etc. personificam o ambiente e evoca a característica do grupo criativo e dinâmico, o painel foi elaborado em adesivos que permite a substituição em momento de necessidade.

\section{Resultados}

O gráfico a seguir mostra os mesmos itens analisados no segundo questionário, onde foram pesquisadas a importância de determinado fator para o usuário, apresentado em mesma ordem para facilitar a comparação. Este gráfico foi obtido pelo questionário de satisfação do projeto executado, aplicado 15 dias depois da mudança efetiva. Elaborado com as mesmas questões de zero (insatisfação) a quinze (satisfação total). Pode-se notar que não houve satisfação em relação a ruídos internos e ventilação.

Com a finalidade de melhorar a integração dos departamentos, a proposta foi eliminar paredes e aumentar a permeabilidade visual com a colocação de vidros, mas isso gerou um problema de ruídos internos, comunicado aos usuários em fase de projeto, contudo priorizou-se a integração.

A ventilação neste caso seria a natural e a insatisfação se deve a limitação da edificação, a sala está cercada por outros ambientes, o que impossibilita a instalação de janela ficando dependente apenas de ar-condicionado para sanar o problema. Aqui foram levantadas duas questões: a questão da consciência ambiental com o gasto de energia e por parte dos usuários femininos que se queixaram de o ar-condicionado que mesmo ajustado devidamente gera um leve desconforto térmico.

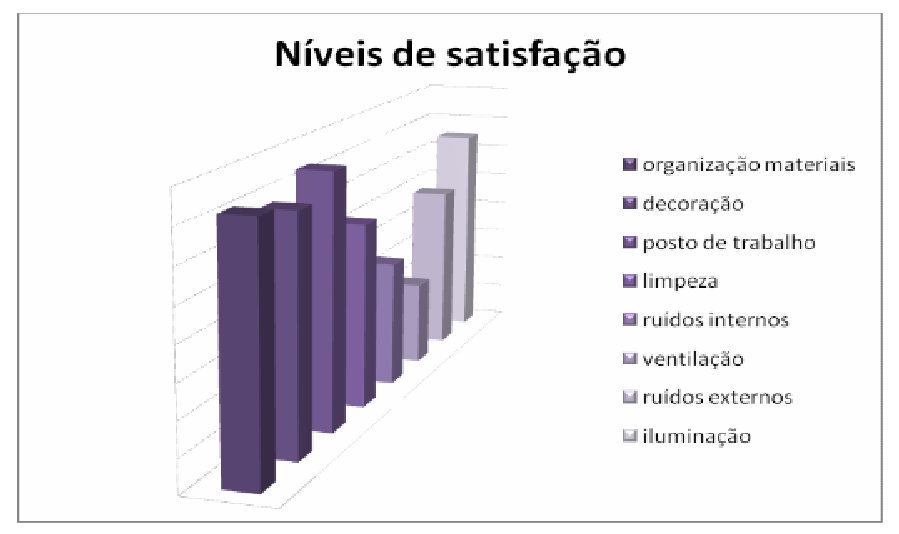

Figura 8 - Gráfico de satisfação - resultado da validação após execução das propostas.

Fonte: Própria.

No questionário anterior a ventilação havia sido considerada apenas a artificial, pois o parâmetro de comparação era a sala anterior onde havia uma janela alta que permitia a boa ventilação natural no período da manhã, mas que gerava o transtorno de poeira excessiva e no período da tarde a insolação na mesma era intensa, portanto a janela em questão era vista como problema a ser sanado.

Mesmo com estes dois fatos que não estão satisfatórios, os usuários de maneira geral aprovaram e preferem esta sala, pois existiu o cuidado em atender as necessidades 
especificadas por cada um, desta maneira o grupo se sente revigorado, estimulados a trabalhar em equipe e possuem um sentimento de pertencimento e preservação do local.

\section{Conclusão}

A busca pela inspiração pode estar ao alcance de todos, com pouco investimento da parte do empregador, mas para isso faz-se necessário um bom planejamento e projetos que possam se renovar de forma fácil, sem gerar transtornos à empresa e seus colaboradores.

Ao iniciar este estudo não era claro ainda o conceito de ambiente de trabalho, pois a intenção era apenas analisá-lo sob os aspectos físicos, palpáveis e projetáveis, entretanto com as evoluções das pesquisas o ambiente psicológico ganhou forças e proporções mais relevantes.

Saber lidar com os diferentes tipos de personalidade, estimular os indivíduos tão peculiares a extraírem o melhor de si para benefício de todos é uma questão de relacionamento, investimento contínuo no indivíduo e no ambiente que o cerca para conseguir o máximo de sua competência criativa e aliar-se ao movimento da pró-atividade, iniciativa e bem coletivo, visando sempre o crescimento da organização. Não há crescimento organizacional sem o crescimento dos grupos e indivíduos que nele se encontram.

Para que o processo criativo evolua naturalmente, além do grupo criativo necessitar de harmonia e ferramentas para desenvolvimento do seu trabalho, precisa também de um ambiente propício ao alcance dessa criatividade que se abastece de sensações e conhecimentos intrínsecos para externá-los em produtividade. A falta de informações subjetivas para alimentar a criatividade pode diminuir o rendimento a médio e curto prazo, os projetos começam a se repetirem ou sua similaridade se torna um agravante, além da fadiga e falta de atenção do funcionário que causam queda na qualidade de serviço.

Planejar o ambiente é tão importante quanto estabelecer metas e objetivos para uma empresa. Não são necessários grandes ajustes ou projetos mirabolantes para manter a mente criativa, mas sim entender que cada grupo de trabalho funciona de determinada maneira e adequar seu posto às suas necessidades, conhecendo de fato quais os anseios da equipe criativa em questão.

1- Corrente de pensamento chinesa originária há mais de quatro mil anos, estruturada a partir do princípio que todo terreno possui sua própria vibração e sofre influências do ambiente que o circunda. Busca o equilíbrio com a natureza, compreenderam a importância de estudar como situar as edificações, móveis e objetos da maneira mais adequada para favorecer seus usuários, gerando vibrações que são benéficas aos seus usuários. Tais sentenças não são endossadas em base científica.

\section{Referências}

ALENCAR, Eunice M. L. Soriano. Promovendo um ambiente favorável à criatividade nas organizações. São Paulo: Revista de Administração de Empresas, 1998.

BIRMAN, Joel. Criatividade e sublimação em psicanálise. Rio de Janeiro: Psicologia clínica, 2008. v.20.

COSTA, Evaldo. Alavancando resultados através da gestão da qualidade. 2.ed. Rio de Janeiro: Jecab, 1999. 
COUTO, Hudson de Araújo. Ergonomia aplicada ao trabalho: manual técnico da máquina humana. Belo Horizonte: ERGO Editora, 1995.

CRESPO, Mari Lucia Figueiredo. Construção e validação de um isntrumento de clima para criatividade nas organizações empresariais. Campinas: PUC, 2005.

DE MASI, Domenico. Criatividade e grupos criativos. Rio de Janeiro: Sextante, 2003. .o Ócio criativo. Rio de Janeiro: Sextante, 2000.

DUL, Jan; WEERDMEESTER, Bernard. Ergonomia prática. São Paulo: Edgard Blücher, 1995.

FARIA, Maria de Fátima Bruno de; ALENCAR, Eunice M.L Soriano de. Estímulos e barreiras à criatividade no ambiente de trabalho. Revista de Administração, São Paulo v.31, n.2, p.5061, .abr./jun. 1996.

GARVIN, David A. Gerenciando a qualidade: a visão estratégica e competitiva. Rio de Janeiro: Qualitymark, 1992.

GOMES, Débora Dias. Fator K: conscientização \& comprometimento: criando qualidade no ambiente da organização. São Paulo: Pioneira, 1994.

GUÉRIM, F. [et al.]. Compreender o trabalho para transformá-lo. São Paulo, Edgard Blücher, 2001.

HALBWACHS, Maurice. A memória coletiva. São Paulo: Centauro, 2004.

IIDA, Itiro. Ergonomia Projeto e Produção. São Paulo: Edgard Blücher, 1990.

MELLO, Carlos Henrique Pereira et al. ISO 9001:2000: sistema de gestão da qualidade para operações de produção e serviço. São Paulo: Ed. Atlas, 2002

MINAYO, M.C.S. (Org.). Pesquisa social: teoria, método e criatividade. Petrópolis: Vozes, 1999.

PINHEIRO, Igor Rezska. Modelo geral da criatividade. Psicologia: Teoria e pesquisa, 2009.

RIVLIN, Leanne G. Olhando o passado e o futuro: revendo pressupostos sobre as interrelações pessoa-ambiente. Estudos de Psicologia, Natal, v.8, n.2, p. 215-220, 2003.

SALES, Anaud. Criatividade, comunicação e produção do saber. Porto Alegre: Sociologias Dossiê ano 10 no 19, 2008.

SPILLER, Eduardo Santiago. Gestão de serviços e marketing interno. Rio de Janeiro: FGV, 2006. 
ZACHARIAS, Oceano. ISO 9001:2008: uma ferramenta de gestão. São Paulo: O.J. Zacharias, 2009.

WISNER, A. Por dentro do trabalho: ergonomia, método \& técnica. São Paulo: FTD: Oboré, 1987. 